\title{
Diyabetik Maküler Ödem Olgularında Optik Koherens Tomografideki Hiperreflektif Noktalar
}

\section{Hyperreflective Spots in Optical Coherence Tomography in Subjects with Diabetic Macular Edema}

\author{
Mahmut KAYA, Sibel DOĞUiż̇i, Çağrı İLHAN ${ }^{3}$ \\ 1 Viranşehir Devlet Hastanesi, Göz Hastalıkları, Şanlıurfa, Türkiye \\ 2 SBÜ Ulucanlar Göz Eğitim ve Araştırma Hastanesi, Göz Hastalıkları, Ankara, Türkiye
}

3 Hatay Eğitim ve Araştırma Hastanesi Hatay, Türkiye

Yazışma Adresi

Correspondence Address

\section{Çağrı İLHAN}

Hatay Eğitim ve Araştırma Hastanesi Hatay, Türkiye

cagriilhan@yahoo.com

Geliş tarihi / Received : Eylül 15, 2020 Kabul tarihi / Accepted : Aralık 08, 2020 Elektronik yayın tarihi : Ocak 01, 2022 Online published

Bu makalede yapılacak atıf: Cite this article as:

Kaya M, Doğuizi S, İlhan Ç. Diyabetik Maküler Ödem

Olgularında Optik Koherens Tomografideki Hiperreflektif Noktalar.

Akd Tip D 2022; 8(1):16-21.

Mahmut Kaya

ORCID ID: 0000-0002-8496-0169 Sibel Doğuizi

ORCID ID: 0000-0001-6047-218X Çağrı İlhan

ORCID ID: 0000-0001-9122-2466

\section{ÖZ}

Amaç:

Diyabetik maküler ödem (DMÖ) tanısı ile takip edilen olguların optik koherens tomografi (OKT) bulgularını incelemek ve bu bulgular ile olguların kliniği arasındaki ilişkiyi analiz etmektir.

\section{Gereç ve Yöntem:}

Bu çalışmada DMÖ olgularının tıbbi kayıtları incelendi. İç limitan membran ile dış nükleer tabaka arasındaki hiperreflektif noktaları iç, daha dış katmanlardaki hiperreflektif noktalar ise dış katlardaki hiperreflektif noktalar olarak gruplandırıldı. Bir başka gruplama ise OKT'de elipsoid zonun (EZ) ve dış limitan membranın (DLM) düzenli bir görünümünün olup olmadığ1na göre yapildı.

\section{Bulgular:}

125 olgunun 167 gözü incelendi. Hiperreflektif noktalar \%94,6 olguda iç retinal katlarda iken \%57,5 olguda dış retinal katlarda idi. \%15,6 olguda EZ bozukluğu mevcut iken yine \%15,6 olguda DLM bozukluğu mevcuttu. En iyi düzeltilmiş görme keskinliği (EİDGK) iç ve diş retinal tabakalarda hiperreflektif nokta bulunan olgularda ve EZ ve DLM bozukluğu bulunan olgularda anlamlı şekilde daha düşüktü (tamamında $\mathrm{p}<0,001$ ). D1ş retinal katmanlardaki hiperreflektif nokta varlığında EZ ve DLM'nin bozuk olma olasılığının yüksek olduğu ( $<<0,001)$, fakat iç retinal katmanlardaki hiperreflektif nokta varlığında EZ ve DLM'deki bozulma olasılığının artmadığı görüldü ( $\mathrm{p}>0,05)$.

\section{Sonuç:}

DMÖ'de hiperreflektif noktalar iç retinal tabakalarda daha sıktır. Hem iç hem de dış retinal tabakalardaki hiperreflektif noktalar düşük görme keskinliği ile ilişkiliyken, sadece dış retinal tabakalardaki hiperreflektif noktaların varlığg EZ ve DLM bozuklukları ile ilişkilidir.

Anahtar Kelimeler: Dış limitan membran, Diyabetik maküler ödem, Elipsoid zon, Hiperreflektif nokta, Optik koherens tomografi

\section{ABSTRACT}

Objective:

To investigate optic coherence tomography (OCT) findings of patients with diabetic macular edema (DME) and to analyze the relationship between these findings and the clinics.

\section{Methods:}

In this study, medical records of DME cases were investigated. Hyperreflective spots between 
Kaya M. ve ark.

inner limiting membrane and outer nuclear layer were determined as hyperreflective spots in inner layers, and those beyond outer nuclear layer were determined as hyperreflective points in outer layers.Another grouping was made according to whether ellipsoid zone (EZ) and external limiting membrane (ELM) had a regular appearance in OCT.

\section{Results:}

167 -eyes of 125 -cases were evaluated.Hyperreflective spots were in the inner retinal layers in $94.6 \%$ of the cases, while they were in the outer retinal layers in $57.5 \%$. EZ disruption was present in $15.6 \%$ of the cases and ELM disruption was present in $15.6 \%$ of the cases. The best corrected visual acuity (BCVA) was significantly lower in the cases that had hyperreflective spots in the inner or outer retinal layers, or had EZ or ELM disruptions $(p<0.001$, for all). In the presence of hyperreflective spots in the outer retinal layers, the probability of disruption in EZ and ELM was high $(p<0.001)$, but probability of disruption in EZ and ELM did not increase in the presence of hyperreflective spots in the inner retinal layers $(\mathrm{p}>0.05)$.

\section{Conclusion:}

In DME, hyperreflective spots are more common in the inner retinal layers. Hyperreflective spots in both inner and outer retinal layers are associated with low visual acuity, while only the presence of hyperreflective spots in the outer retinal layers is associated with EZ and ELM disruptions.

Key Words: Diabetic macular edema, Ellipsoid zone, External limiting membrane, Hyperreflective spot, Optical coherence tomography

\section{GIRIŞ}

Diyabetik maküler ödem (DMÖ), diyabetik retinopatinin herhangi bir evresinde görülebilen ve diyabetes mellitusun görme kaybı ile sonuçlanan en sık komplikasyonudur $(1,2)$. DMÖ patogenezine katkıda bulunan birçok yolak vardır fakat bunların içinde en iyi bilineni vasküler endotelyal büyüme faktörü ile ilişkili olan yolaktır. Bu yolakta inflamatuar hücre göçü ve adezyonu artmakta ve endotelde fonksiyon kaybıyla beraber iç kan-retina bariyeri bozulmaktadır. Böylece biriken intraretinal ve subretinal sivı makula yapısını ve fonksiyonunu bozmaktadir $(3,4)$.

Optik koherens tomografi (OKT), retinanın anatomik tabakaları hakkında niceliksel ve niteliksel bilgi sağlayan girişimsel olmayan, temassız bir tanı yöntemidir (5). OKT yardımıyla DMÖ tanı ve takibinde objektif değerlendirme yapma imkânı sağlanmıştır $(6,7)$. DMÖ olgularındaki retinal kalınlaşma OKT'de intraretinal kistoid boşluklar veya subretinal sıv1 şeklinde bulgu vermektedir. Retinal mimarinin bozulmasına bağlı olarak normalde var olan hiporeflektif veya hiperreflektif bantların bozulması ve ilave hiperreflektif nokta veya alanların oluşması da DMÖ ile ilişkili diğer OKT bulgularıdır $(8,9)$. Bu çalışmanın amacı, DMÖ tanısı ile kliniğimizde takip edilen olguların başvuru anındaki OKT bulgularını incelemek ve bu bulgular ile olguların kliniği arasındaki ilişkiyi detaylı analiz etmektir.

\section{GEREÇ ve YÖNTEM}

$\mathrm{Bu}$ geriye dönük, gözlemsel, vaka kontrol çalışması 1964 Helsinki Bildirgesi'nde belirtilen etik standartlarına göre yapıldı ve araştırma ve yayın etiğine uyuldu. Ankara Numune Eğitim ve Araştırma Hastanesi Klinik Araştırmalar Etik Kurulu tarafindan onay alındı (14/12/2016, E-16-1102). Ocak 2014 ile Haziran 2016 tarihleri arasında, bir üçüncü basamak hastanenin retina birimine başvuran DMÖ olgularının tıbbi kayıtları geriye dönük olarak incelendi. Kayıtlarında detaylı tıbbi öyküsü olan ve DMÖ varlığı tam bir oftalmolojik muayene, OKT ve flöresein anjiografi ile doğrulanmış ve herhangi bir tedavi görmemiş veya takiplerine ara vermesi dolayısıyla (genellikle il dışı veya kırsal kesimden başvuran yaşlı hastalar) son 3 ay içinde tedavi yapılmamış olgular çalışmaya dahil edildi. Arka segment muayenesini veya OKT değerlendirmesini engelleyen ortam opasiteleri (yoğun katarakt veya vitre içi hemoraji), glokom, optik sinir bozuklukları, üveit ve diğer retina hastalıkları veya retinal bulgu verebilecek sistemik hastalığ 1 olan olgular çalışmaya dahil edilmedi. Sonuç olarak tıbbi kayıtları tam olan ve optimum OKT değerlendirmesi yapılan 125 olgunun 167 gözü çalışmaya dahil edildi. Çalışmanın tüm aşamaları Helsinki Bildirgesi’ne uygun olacak şekilde tasarlandi.

Olguların yaş, cinsiyet, hipertansiyon varlığı ve diyabetik retinopatinin varlığı ve evresi (ETDRS kılavuzuna göre) gibi bulguları kaydedildi. Snellen eşeli kullanılarak ölçülen en iyi düzeltilmiş görme keskinliği (EIDGK) değerleri istatistiksel değerlendirme için $\log$ MAR değerlerine çevrildi. OKT (Spectralis, Heidelberg, Almanya) bulguları aynı retina uzmanı tarafindan incelendi. B mod taramada foveaya en yakın kesit merkez kabul edildi ve bunun üzerindeki ve altındaki $1 \mathrm{~mm}$ genişliğindeki 3 kesit alanı incelendi. Retina katmanlarındaki küçük, punktat, izole, beyaz lezyonlar hiperreflektif noktalar olarak tanımland. Sert eksudalar ile uyumlu anormallikler de hiperreflektif nokta olarak değerlendirilirken geniş oturmuş subfoveal eksudalar bu kategoriye dahil edilmedi. İç limitan membran ile dış nükleer tabaka arasındaki hiperreflektif noktaları iç, daha dış katmanlardaki hiperreflektif noktalar ise dış katlardaki hiperreflektif noktalar olarak gruplandırıldı. OKT'de elipsoid zonun (EZ) (önceki adı ile IS/OS bandının) ve dış limitan membranın (DLM) düzenli bir görünümünün olup olmadığı değerlendirildi ve sürekli lineer çizgi oluşturanlar sağlam, oluşturmayanlar bozuk olarak gruplandırıldı.

İstatistiksel değerlendirme için Statistical Package for Social Sciences (SPSS) 20.0 paket programı kullanıldı. Verilerin normal dağılıma uygunluğu Kolmogorov-Smirnov testi ile değerlendirildi. Gruplar arası karşılaştırmalarda normal dağılıma uyan veriler için Student-t testi, normal dağılıma uymayan veriler için Mann-Whitney $U$ testi ve kategorik veriler için ki-kare ve Fisher's exact testleri uygulandı. Korelasyon analizi için Pearson korelasyon analizi kullanıldı. Tüm istatistiksel veriler için $\mathrm{p}<0,05$ değeri anlamlı kabul edildi.

\section{BULGULAR}

Çalışmaya dahil edilen 125 DMÖ olgusunun 167 gözü incelendi. Olguların yaş ortalaması 59,43 \pm 7,35 yıl (27 - 84) 
Diyabetik Maküler Ödem Olgularında Optik Koherens Tomografideki Hiperreflektif Noktalar

olup \%57,5'i erkek, \%42,5'i ise kadınd. Olguların \%45,5'inde sistemik hipertansiyon mevcuttu. Olguların \%12,0'1nda tip-1, \%88,0'1nda tip-2 diyabetes mellitus mevcuttu. Diyabetik retinopatinin evresi olguların \%36,5'inde hafif-orta nonproliferatif diyabetik retinopati, $\% 36,5$ 'inde ciddi nonproliferatif diyabetik retinopati ve $\% 26,9$ 'unda proliferatif diyabetik retinopati idi. Ortalama EIDGK ise 0,61 $\pm 0,29$ $\operatorname{logMAR}(0,10-1,20)$ idi. Çalışma grubunun detaylı demografik ve klinik özellikleri Tablo I'de verilmektedir.

Tablo I. Çalışma grubunun detaylı demografik ve klinik özellikleri.

\begin{tabular}{|c|c|}
\hline Yaș (yl), ortalama \pm standart sapma (minimum - maksimum) & $59,43 \pm 7,35(27-84)$ \\
\hline \multicolumn{2}{|l|}{ Cinsiyet, $\mathrm{n}(\%)$} \\
\hline Erkek & $96(57,5)$ \\
\hline Kadın & $71(42,5)$ \\
\hline \multicolumn{2}{|l|}{ Taraf, n (\%) } \\
\hline Sağ & $83(49,7)$ \\
\hline Sol & $84(50,3)$ \\
\hline \multicolumn{2}{|l|}{ Hipertansiyon, $\mathrm{n}(\%)$} \\
\hline Var & $76(45,5)$ \\
\hline Yok & $91(54,5)$ \\
\hline \multicolumn{2}{|l|}{ Diyabetes mellitus tipi, $\mathrm{n}(\%)$} \\
\hline Tip-I & $20(12,0)$ \\
\hline Tip-II & $147(88,0)$ \\
\hline \multicolumn{2}{|l|}{ Diyabetik retinopati evresi, $\mathrm{n}(\%)$} \\
\hline Hafif-orta nonproliferatif diyabetik retinopati & $61(36,5)$ \\
\hline Ciddi nonproliferatif diyabetik retinopati & $61(36,5)$ \\
\hline Proliferatif diyabetik retinopati & $45(26,9)$ \\
\hline $\begin{array}{l}\text { En iyi düzeltilmiş görme keskinliği (LogMAR), ortalama } \pm \\
\text { standart sapma (minimum - maksimum) }\end{array}$ & $0,61 \pm 0,29(0,10-1,20)$ \\
\hline
\end{tabular}

OKT'de ölçülen santral foveal kalınlık ortalaması 492,7 \pm 150,7 $\mu \mathrm{m}(300$ - 906) idi. \%94,6 olguda iç retinal katlarda, $\% 57,5$ olguda ise diş retinal katlarda hiperreflektif nokta mevcuttu. \%15,6 olguda EZ bozukluğu mevcut iken yine \%15,6 olguda DLM bozukluğu mevcuttu. Olguların OKT bulguları Tablo II'de özetlenmektedir.

Tablo II. Olguların spektral domain optik koherens tomografi bulgular1.

\begin{tabular}{|c|c|}
\hline $\begin{array}{l}\text { Santral Foveal Kalınlık }(\mu \mathrm{m}) \text {, ortalama } \pm \text { standart sapma } \\
\text { (minimum - maksimum) }\end{array}$ & $492,7 \pm 150,7(300-906)$ \\
\hline İç Retinal Katlarda Hiperreflektif Nokta, n (\%) & $158(94,6)$ \\
\hline Dış Retinal Katlarda Hiperreflektif Nokta, n (\%) & $96(57,5)$ \\
\hline \multicolumn{2}{|l|}{ Dış Limitan Membran, n (\%) } \\
\hline Bozuk & $26(15,6)$ \\
\hline İntakt & $141(84,4)$ \\
\hline \multicolumn{2}{|l|}{ Elipsoid Zon, n (\%) } \\
\hline Bozuk & $26(15,6)$ \\
\hline İntakt & $141(84,4)$ \\
\hline
\end{tabular}

EIDGK ile santral foveal kalınlık arasında pozitif yönde, güçlü düzeyde, istatistiksel anlamlı ilişki saptandı $(r=0,714$ ve $p<0,001)$. Şekil 1 EIDGK ile santral foveal kalınlık arasındaki ilişkiyi şematize etmektedir.

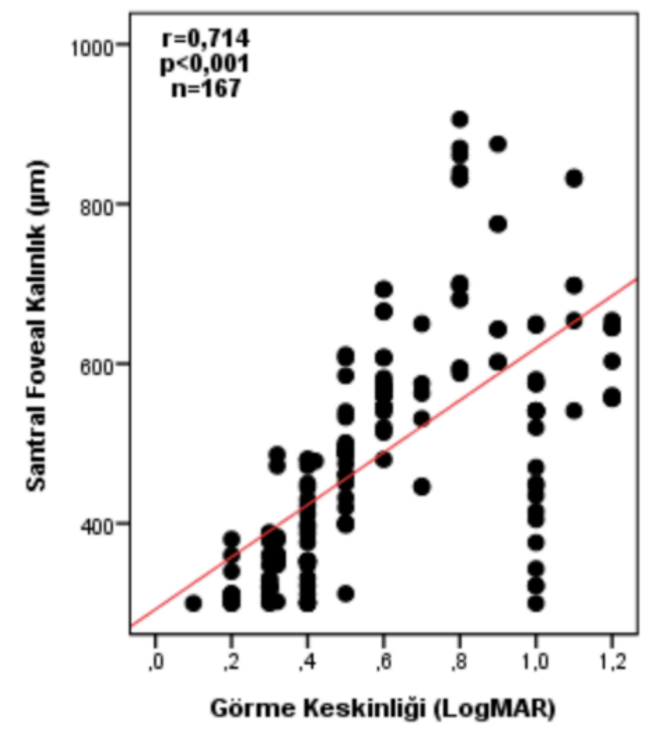

Şekil 1. En iyi düzeltilmiş görme keskinliği ile santral foveal kalınlık arasındaki ilişki.

Ayrıca EIDGK iç ve dış retinal tabakalarda hiperreflektif nokta bulunan olgularda bulunmayanlara göre anlamlı olarak daha düşüktü ( $p<0,001$ her ikisi için). Benzer şekilde EIDGK EZ ve DLM bozukluğu bulunan olgularda bulunmayanlara kıyasla anlamlı şekilde daha düşüktü ( $<<0,001$ her ikisi için). EIDGK ile SD-OKT bulguları arasındaki ilişki Tablo III’te özetlenmektedir.

Tablo III. Spektral domain optik koherens tomografi ile en iyi düzeltilmiş görme keskinliği arasındaki ilişki.

\begin{tabular}{|c|c|c|c|}
\hline & \multicolumn{2}{|c|}{$\begin{array}{c}\text { En iyi düzeltilmiş görme } \\
\text { Keskinliği (LogMAR) }\end{array}$} & \multirow{2}{*}{ p } \\
\hline & $\mathrm{n}$ & $\begin{array}{l}\text { Ortalama } \pm \text { standart sapma } \\
\text { (minimum - maksimum) }\end{array}$ & \\
\hline \multicolumn{4}{|c|}{ İç Retinal Katlarda Hiperreflektif Nokta } \\
\hline $\begin{array}{l}\text { Var } \\
\text { Yok }\end{array}$ & $\begin{array}{c}158 \\
9\end{array}$ & $\begin{array}{c}0,63 \pm 0,29(0,1-1,2) \\
0,32 \pm 0,07(0,3(0,2-0,4)\end{array}$ & $<0,001$ \\
\hline \multicolumn{4}{|c|}{ Dış Retinal Katlarda Hiperreflektif Nokta } \\
\hline $\begin{array}{l}\text { Var } \\
\text { Yok }\end{array}$ & $\begin{array}{l}96 \\
71\end{array}$ & $\begin{array}{l}0,75 \pm 0,25(0,1-1,2) \\
0,43 \pm 0,23(0,2-1,2)\end{array}$ & $<0,001$ \\
\hline \multicolumn{4}{|c|}{ Dış Limitan Membran } \\
\hline $\begin{array}{l}\text { Bozuk } \\
\text { İntakt }\end{array}$ & $\begin{array}{l}26 \\
141\end{array}$ & $\begin{array}{l}1,05 \pm 0,09(0,8-1,2) \\
0,53 \pm 0,24(0,1-1,2)\end{array}$ & $<0,001$ \\
\hline \multicolumn{4}{|c|}{ Elipsoid Zon } \\
\hline $\begin{array}{l}\text { Bozuk } \\
\text { İntakt }\end{array}$ & $\begin{array}{l}26 \\
141\end{array}$ & $\begin{array}{l}1,05 \pm 0,09(0,8-1,2) \\
0,53 \pm 0,24(0,1-1,2)\end{array}$ & $<0,001$ \\
\hline
\end{tabular}


Kaya M. ve ark.

EZ ve DLM durumu göz önünde bulundurulduğunda, dış retinal katmanlardaki hiperreflektif nokta varlığında EZ ve DLM'nin bozuk olma olasılığının istatistiksel anlamlı olarak yüksek olduğu görüldü $(\mathrm{p}<0,001)$. Aksine iç retinal katmanlardaki hiperreflektif nokta varlığında EZ ve DLM'deki bozulma olasılığının artmadığı görüldü ( $p>0,05)$. Tablo IV iç ve dış retinal tabakalardaki hiperreflektif noktaların varlığı ve EZ ve DLM durumu arasındaki ilişki hakkındaki detayları vermektedir.

Tablo IV. İç ve dış retinal tabakalardaki hiperreflektif noktaların varlığı ve elipsoid zon ve eksternal limitan membran durumu arasındaki ilişki.

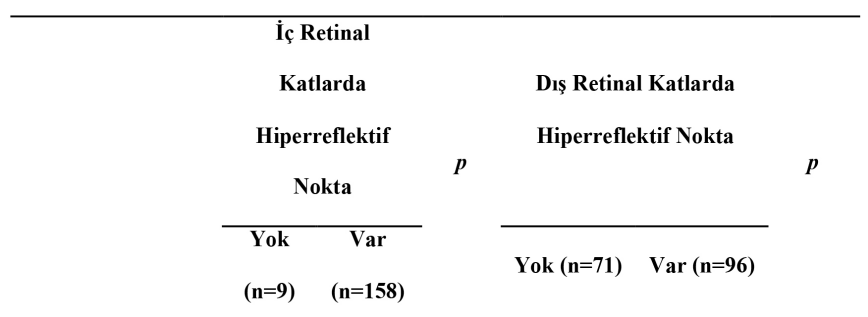

\begin{tabular}{lcccccc}
\hline \multicolumn{1}{l}{ Diş Limitan Membran, $\mathrm{n}(\%)$} & & & & & \\
İntakt & $9(100)$ & 132 & & $71(100)$ & $70(72,9)$ & \\
& & $(83,5)$ & $0,357^{\#}$ & & & $<0,001^{*}$ \\
Bozuk & 0 & $26(16,5)$ & 0 & $26(27,1)$ & \\
\hline Elipsoid Zon, n (\%) & & & & & & \\
İntakt & $9(100)$ & 132 & & $71(100)$ & $70(72,9)$ & \\
& & $(83,5)$ & $0,357^{\#}$ & & & $<0,001^{*}$ \\
Bozuk & 0 & $26(16,5)$ & 0 & $26(27,1)$ & \\
\hline
\end{tabular}

*Ki-Kare Testi; \#Fisher'in Kesin Testi

\section{TARTIŞMA}

DMÖ, diyabetes mellitus hastalarında görsel kötüleşmenin en s1k sebebidir ve OKT hastalığın tanı ve takibinde kullanılan altın standart bir yöntemdir $(1,2)$. Ayrıca OKT'nin çabuk uygulanabilirliği, girişimsel olmaması ve tekrarlanabilirliği göz önünde bulundurulduğunda eşsiz bir yere sahiptir (10). Bununla birlikte sadece OKT ile tanımlanan patolojiler ve kavramların olması DMÖ'de patogenezin, tedaviye cevabın ve prognozun belirlenmesinde yeni ufuklar açılmasını sağlamaktadır. Bu çalışmada DMÖ olgularında hiperreflektif noktaların varlığı ve konumu, santral foveal kalınlık, EZ ve DLM gibi retinal morfolojik yapılar OKT yöntemi ile incelendi ve EIDGK gibi klinik verilerle ilişkisi araştırıldı. Gerek bahsedilen retinal morfolojik yapıların detaylı incelenmesi gerek çalışmadaki Türkiye ve ağırlıklı olarak Orta Anadolu popülasyonuna dahil örneklemin büyüklüğü çalışmanın en öne çıkan özellikleridir.

Uji ve ark. (10) bu çalışmadakine benzer bir yöntemle yaptıkları çalışmalarında hiperreflektif nokta varlığını iç retinal katlarda \%99,1 ve dış retinal katlarda \%53,7 oranında bildirmişlerdir. $\mathrm{Bu}$ bakımdan değerlendirildiğinde çalışmada bildirilen oran literatür bilgileriyle oldukça uyumludur. Şabaner ve ark. (11) DME olgularında hiperreflektif nokta varlığını inflamasyon lehine bir durum olarak tanımlamışlardır. Bu çalışmada olguların \%94,6'sında iç retinal katlarda hiperreflektif noktalar varken \%57,5'sinde diș retinal katlarda hiperreflektif noktalar vard1. Bununla birlikte hiperreflektif noktaların etyopatogenezi konusunda ortak bir görüş bulunmamaktadır. Bu konuda kabul gören 2 teoriden birincisinde; hiperreflektif noktaların eksudaların öncülü olan ekstravaze olmuş lipoproteinler olduğu iddia edilmektedir (12). Benzer bulguların retinal ven tıkanıklıklarında da görülmeleri bu teoriyi desteklemektedir (13). Fakat Turgut ve ark. (14) yaptıkları bir çalışmada diyabetik retinopati ve retinal ven tıkanıklığı gibi sıklıkla eksuda ile seyreden durumların dışlandığı serilerinde yine de hiperreflektif noktalara rastlandığını bildirmişlerdir. Bu konudaki bir başka hipotez hiperreflektif noktaların aktive olmuş mikroglialar olduğu şeklindedir ve bu hipotez de retinopati olmayan hastalarda da hiperreflektif noktaların gösterilmesiyle desteklenmektedir (15). Aslında diyabetik retinopatideki mikroglia aktivitesi histopatolojik olarak gösterilmiştir (16). Üstelik bu hiperreflektif noktalar mikrogliaların hareket paternini taklit edecek şekilde ilk aşamada iç retina katlarında bulunup, sonraki aşamalarda retina dış katlarında görülmeye başlanmaktadır (15). Bu çalışmada hiperreflektif noktaların iç retina katlarında dış katlardan daha fazla bildirilmesi de bu hipotezi destekleyen bir başka durumdur.

Çalışmanın sonuçlarına göre olgulardaki EZ ve DLM bozukluğu oranları birbirine eşittir. Dış retinal tabakalarda hiperreflektif nokta bulunması ile EZ ve DLM bozukluğu arasında anlamlı ilişki vardır. EZ ve DLM fotoreseptör bütünlüğünün bir göstergesidir ve bu diş retinal katmanlarda hiperreflektif nokta bulunmasının görme keskinliğini düşürmesini açıklayabilir. Literatürde dış retinal katmanlardaki hiperreflektif noktaların varlığı ile görme keskinliğinin azaldığını bildiren başka çalışmalar da vardır (10). Fakat sebep sonuç ilişkisinin farklı olabileceğini de akılda tutmak gerekir. DLM, Müller hücreleri ile fotoreseptörler arasında bariyer fonksiyonu görmektedir ve DLM'nin bozulması, bu bariyer fonksiyonunu bozarak, aktive mikrogliaların retinanın dış katmanlarına göç etmesine sebep olmuş olabilir. Ayrıca diş retinal katmanlarda hiperreflektif noktaların daha ileri aşama diyabetik retinopatide ortaya çıkması da bu hipotezi desteklemektedir.

Çalışmanın sonuçlarına göre santral foveal kalınlık artışı ile görme keskinliği arasında pozitif yönlü, güçlü bir ilişki vardır. Literatürde konu ile alakalı çelişkili sonuçlar bildirilmektedir. Mimouni ve ark. (17) santral foveal kalınlık ile görme keskinliği arasında DMÖ’lü hastalarda ılımlı ilişki bulmuşken ven dal tıkanıklığına bağlı maküler ödemde daha güçlü bir ilişkiden bahsetmektedir. Browning ve ark. (18) da benzer şekilde santral foveal kalınlık ile görme keskinliği arasında 1lımlı ilişki vardır demiştir. Fakat Diyabetik Retinopati Klinik Araştırma Ağı'nın yaptığı çalışmada santral foveal kalınlıkta artışa rağmen görme keskinliğinin paradoksik olarak artabildiği ya da santral foveal kalınlıkta azalmaya rağmen görme keskinliğinin paradoksik olarak düşebildiği ifade edilmiştir (18). Tüm bunların dışında Murakami ve ark. (19) DMÖ olgularında vitrektomi öncesi iç retinal katlarda kalınlaşmanın görme keskinliği ile pozitif yönde ilişkili olduğunu, diş retinal katlarda kalınlaşmanın ise negatif yönde ilişkili olduğunu ifade etmişlerdir. 
Söz konusu çalışmanın en önemli kısıtlılı̆̆ı retrospektif tasarımıdır. SD-OKT bulgularının tek retina uzmanı tarafından incelenmesi de bir başka kısıtlılığıdır. Çalışmaya 3 aydan uzun süredir tedavi yapılmamış hastaların dahil edilerek tedaviye bağlı OKT bulgularındaki değişikliklerin inceleme alanı dışında bırakılması amaçlanmışsa da bu hastaları bütünüyle tedavi görmemiş hastalar olarak kabul etmek zordur. SD-OKT bulgularının tedavi üzerine nasıl etki ettiğinin incelendiği prognostik faktörlerin belirlendiği, prospektif, çok merkezli ve uzun takip süreli çalışmalar daha değerli bilgiler verecektir.

\section{SONUÇ}

DMÖ olgularında hiperreflektif noktalara iç retinal tabakalarda daha sık rastlanmaktadır. Hem iç hem de dış retinal tabakalardaki hiperreflektif noktaların varlığı düşük görme keskinliği ile ilişkiliyken, sadece diş retinal tabakalardaki hiperreflektif noktaların varlığı EZ ve DLM bozuklukları ile ilişkilidir. Bu çalışma literatüre DMÖ olgularındaki hiperreflektif noktalar ve klinik önemi konulu çalışmalara Türkiye ve ağırlıklı olarak Orta Anadolu popülasyonunu araştırmış olması bakımından katkı sağlamaktadır.
Finansman veya Mali Destek: Herhangi bir finansman veya mali destek kullanılmamıştır.

Çıkar Çatışması: Herhangi bir çıkar çatışması bildirilmemektedir.

\section{Yazarların Katkısı:}

Çalışmanın konsepti ve dizaynı: MK; SD; Çİ Verilerin toplanması ve işlenmesi: MK; SD; Çİ Verilerin analizi ve yorumlanması: MK; SD; ÇI Literatür araştırması: MK; SD; ÇI Makalenin yazımı: MK; SD; Çİ Kritik gözden geçirme: MK; SD; Çİ Yayınlanacak versiyonun nihai onayı: MK; SD; ÇI

Etik Kurul Onay Bilgisi: Ankara Numune Eğitim ve Araştırma Hastanesi Klinik Araştırmalar Etik Kurulu tarafından onay alınmıştır (14/12/2016, E-16-1102). 
Kaya M. ve ark.

\section{KAYNAKLAR}

1. Yoshida S, Murakami T, Nozaki M, Suzuma K, Baba T, Hirano T, Sawada O, Sugimoto M, Takamura Y, Tsuiki E. Review of clinical studies and recommendation for a therapeutic flow chart for diabetic macular edema. Graefes Arch Clin Exp Ophthalmol 2021; 259: 815-836.

2. Chung YR, Kim YH, Ha SJ, Byeon HE, Cho CH, Kim $\mathrm{JH}$, Lee K. Role of Inflammation in Classification of Diabetic Macular Edema by Optical Coherence Tomography. J Diabetes Res 2019; 2019: 8164250.

3. Zhang X, Zeng H, Bao S, Wang N, Gillies MC. Diabetic macular edema: new concepts in patho-physiology and treatment. Cell Biosci 2014; 14: 4:27.

4. İlhan Ç. Diyabetik maküler ödemde görüntüleme. Mersin Univ Saglik Bilim Derg 2018; 11: 376-382.

5. Kostanyan T, Wollstein G, Schuman JS. New developments in optical coherence tomography. Curr Opin Ophthalmol 2015; 26:110-115.

6. Kwan CC, Fawzi AA. Imaging and Biomarkers in Diabetic Macular Edema and Diabetic Retinopathy. Curr Diab Rep 2019; 19:95.

7. Chung H, Park B, Shin HJ, Kim HC. Correlation of fundus autofluorescence with spectral-domain optical coherence tomography and vision in diabetic macular edema. Ophthalmology 2012; 119: 1056-1065.

8. Danis RP, Hubbard LD. Imaging of diabetic retinopathy and diabetic macular edema. Curr Diab Rep 2011; 11: 236-243.

9. Çıtırık M, İlhan Ç, Teke MY. Optik koherens tomografi. Güncel Retina 2017; 1: 58-68.

10. Uji A, Murakami T, Nishijima $\mathrm{K}$, Akagi $\mathrm{T}$, Horii $\mathrm{T}$, Arakawa N, Muraoka Y, Ellabban AA, Yoshimura N. Association Between Hyperreflective Foci in the Outer Retina, Status of Photoreceptor Layer, and Visual Acuity in Diabetic Macular Edema. Am J Ophthalmol 2012; 153: $710-717$.

11. Sabaner MC, Akdogan M, Doğan M, Oral AY, Duman R, Koca T, Bozkurt E. Inflammatory cytokines, oxidative and antioxidative stress levels in patients with diabetic macular edema and hyperreflective spots. Eur J Ophthalmol 2020; 1120672120962054. doi:

$10.1177 / 1120672120962054$.
12. Bolz M, Schmidt-Erfurth U, Deak G, Mylonas G, Kriechbaum K, Scholda C. Diabetic Retinopathy Research Group Vienna. Optical coherence tomographic hyperreflective foci: a morphologic sign of lipid extravasation in diabetic macular edema. Ophthalmology 2009; 116: 914-920.

13. Ogino K, Murakami T, Tsujikawa A, Miyamoto K, Sakamoto A, Ota M, Yoshimura N. Characteristics of optical coherence tomographic hyperreflective foci in retinal vein occlusion. Retina 2012; 32: 77-85.

14. Turgut B, Yildirim H. The causes of hyperreflective dots in optical coherence tomography excluding diabetic macular edema and retinal venous occlusion. Open Ophthalmol J 2015; 9: 36-40.

15. Vujosevic S, Bini S, Midena G, Berton M, Pilotto E, Midena E. Hyperreflective intraretinal spots in diabetics without and with nonproliferative diabetic retinopathy: an in vivo study using spectral domain OCT. J Diabetes Res 2013; 2013: 491835.

16. Ibrahim AS, El-Remessy AB, Matragoon S, Zhang W, Patel Y, Khan S, Al-Gayyar MM, El-Shishtawy MM, Liou GI. Retinal microglial activation and inflammation induced by amadoriglycated albumin in a rat model of diabetes. Diabetes 2011; 60: 1122-1133.

17. Mimouni M, Nahum Y, Levant A, Levant B, Weinberger D. Cystoid macular edema: a correlation between macular volumetric parameters and visual acuity. Can J Ophthalmol 2014; 49: 183-187.

18. Browning DJ, Glassman AR, Aiello LP, Beck RW, Brown DM, Fong DS, Bressler NM, Danis RP, Kinyoun JL, Nguyen QD, Bhavsar AR, Gottlieb J, Pieramici DJ, Rauser ME, Apte RS, Lim JI, Miskala PH. Relationship between optical coherence tomography-measured central retinal thickness and visual acuity in diabetic macular edema. Ophthalmology 2007; 114: 525-536.

19. Murakami T, Nishijima K, Akagi T, Uji A, Horii T, Ueda-Arakawa N, Muraoka Y, Yoshimura N. Segmentational analysis of retinal thickness after vitrectomy in diabetic macular edema. Invest Ophthalmol Vis Sci 2012; 53: 6668-6674. 